\title{
A PANDEMIA COM REFLEXO NO CLIMA DAS INSTITUIÇÕES EDUCACIONAIS: INSTABILIDADE E 0 ACENTUADO ÍNDICE DE INCIVILIDADES NAS RELAÇÕES.
}

\author{
ELIANE PRALON ${ }^{*}$
}

\section{RESUMO}

O Conselho Nacional de Educação (CNE) aprovou, por unanimidade, nesta terça-feira, 28 de abril, as diretrizes para orientar escolas da educação básica e instituições de ensino superior durante a pandemia. O presente estudo, tem por objetivo analisar o período inicial da crise pandêmica e os ajustes dos profissionais da área educacional. Teremos como objeto de estudo uma instituição escolar privada e filantrópica, localizada na Zona Sul da cidade de São Paulo. Trataremos das mudanças repentinas no hábito educacional e os ajustes necessários para o período de limitações impostas pela Covid 19, partindo das condições de trabalho dos professores, das implantações de novas metodologias, sem deixar de lado as relações dos envolvidos. Todas essas questões agregadas às incertezas e inseguranças nos processos pedagógicos, econômicos e na saúde exigiram uma completa reestruturação na maneira de se apresentar o conteúdo educacional, a fim de não comprometer a autonomia do educador, e o desenvolvimento de um clima colaborativo entre as famílias, a gestão e os docentes. Palavras-chave: Clima. Pandemia. Instabilidade.

* Aluna do programa de Mestrado em Educação da Universidade Metodista de São Paulo. 


\begin{abstract}
The National Council of Education (CNE) unanimously approved this Tuesday, April 28, the guidelines to guide basic education schools and higher education institutions during the pandemic. This study aims to analyze the initial period of the pandemic crisis and the adjustments made by professionals in the educational field. We will have as object of study a private and philanthropic School Institution, located in the South Zone of the city of São Paulo. We will deal with the sudden changes in the educational habit and the necessary adjustments for the period of limitations imposed by the covid 19, starting from the working conditions of the teachers of the implementation of new methodologies, without leaving aside the relationships of those involved. All these issues, added to the uncertainties and insecurities in the pedagogical, economic and health processes, demanded a complete restructuring in the way of presenting the educational content, in order not to compromise the autonomy of the educator, and the development of a collaborative atmosphere between families, management and teachers.
\end{abstract}

\title{
INTRODUÇÃO
}

Em cada época histórica, os modos de viver dominantes (trabalho, consumo, lazer, convivência) e de antecipar ou adiar a morte são relativamente rígidos e parecem decorrer de regras escritas na pedra da natureza humana. É verdade que eles se vão alterando paulatinamente, mas as mudanças passam quase sempre despercebidas. A irrupção de uma pandemia não se compagina com esta morosidade. Exige mudanças drásticas. (SANTOS, 2020, p. 5).

A citação acima nos dá uma dimensão de que tudo ou quase tudo foi alterado a partir da chegada dessa pandemia; e na educação não seria diferente, as mudanças repentinas e as 
devidas condições que se deram suscitaram a implantação de novas metodologias.

A transmissão dos saberes (conhecimento) passou por significativas transformações. $\mathrm{O}$ que antes era uma aula em que bastava ao educador apenas transmitir conhecimento de forma verbal e presencial, agora é praticamente impossível em virtude das medidas de isolamento social propostas pela Organização Mundial da Saúde. As primeiras medidas que os governantes adotaram foi a cessação das aulas em todos os níveis (ensino básico, fundamental e superior).

O mundo precisou "reinventar-se" de forma presencial havia limitações (por parte tanto do aluno, quanto do professor, por diversos fatores que não será possível explicitar e por não ser o objeto desse estudo), agora o ambiente virtual para o aprendizado pedagógico passou a ser uma questão de "vida ou morte" na transmissão dos saberes.

Os educadores e gestores educacionais passaram a ter que "cavar fundo" e até vencer suas limitações com o uso da tecnologia ( $\operatorname{sim}$, porque existem pessoas que são avessas ao uso da tecnologia) para que o saber chegue finalmente ao aluno. Agora se faz necessário colocar o saber na plataforma digital; e não apenas isso, visto que o professor tem que se tornar um "ator" diante da tela do computador, do celular ou de outro meio digital.

Freire (2011, p. 52-53) compactuava da ideia de "adequação" por sermos incompletos: "Gosto de ser gente porque, inacabado, sei que sou um ser condicionado, mas, consciente do inacabado sei que posso ir mais além dele”.

Todas essas adequações, agregadas às incertezas e inseguranças de que o desconhecido pode provocar no processo pedagógico, bem como a interação entre os discentes e os docentes que via de regra era aplicada no formato presencial, agora precisam encontrar outra alternativa no formato on-line. Outro fator importante seria colocar em análise as implicações econô- 
micas, sociais, que afetam diretamente a saúde, seja ela física ou emocional da comunidade escolar, de modo a não comprometer a autonomia e o bom clima entre os que a compõe.

A pandemia e a quarentena estão a revelar que são possíveis alternativas, que as sociedades se adaptam a novos modos de viver quando tal é necessário e sentido como correspondendo ao bem comum. Esta situação torna-se propícia a que se pense em alternativas ao modo de viver, de produzir, de consumir e de conviver nestes primeiros anos do século XXI. (SANTOS, 2020, p. 28).

Compreender novas metodologias não é necessariamente esquecer dos processos vividos, mas adequá-los ao novo momento. Gosto de guardar as sábias palavras de Saint-Exupéry (1980, p. 16), quando escreve carta a um refém:

Se, ao escalar uma montanha na direção de uma estrela, o viajante se deixa observar demasiadamente pelos problemas da escalada, ele está arriscando-se a esquecer qual a estrela que o guia... Se o sacristão se preocupa demais com a posição dos bancos, arrisca-se a esquecer que está servindo a um Deus.

Foram apresentadas num questionário perguntas relacionadas a essa nova realidade, sem que as pessoas necessitassem se identificar. A investigação mostrou que o fator tempo afetou toda a classe no tocante à adequação, partindo da elaboração de aulas ao tempo de execução da mesma.

Outro ponto relevante exposto é que 100\% (cem por cento) dos entrevistados são casados e 65\% (sessenta e cinco por cento) possuem filhos em idade escolar, ou seja, enfrentam dupla ou tripla jornada de atividades, posto que, além de administrar o tempo dedicado aos afazeres de casa, precisam acompanhar os filhos em 
sua nova realidade educacional, podendo conflitar os horários de acompanhamento com os de seu trabalho. A preocupação com prazos, adequações e elaboração das atividades, interações on-line (aulas remotas) e off-line (e-mails) se acentuou demasiadamente.

Novos conhecimentos tecnológicos foram necessários, sem mais tempo suplementar para adequação, o que poderia ter sido diferente se, na referida instituição, houvessem sido implantadas aulas ou monitorias on-line em suas práticas diárias antes da pandemia.

Assim, de uma hora para a outra o professor precisou trocar o quadro branco e o seu pincel pela tela do seu celular, notebook, tablete e familiarizar-se com salas de videoconferência, compartilhamento de telas e avaliações on-line, sem contar as videoaulas que deveriam ser gravadas e posteriormente disponibilizadas aos alunos, processo que incomodou muito os educadores.

Os números apresentaram o percentual de 65,2\% (sessenta e cinco vírgula dois por cento) de alterações para as novas práticas educacionais, valor acima da média. Todas as mudanças são bem-vindas especialmente quando agregam conhecimentos, mas isso gerou desestabilidade e provocou um clima nada favorável nas relações internas e externas no tocante à comunidade escolar.

E agora? Surgem várias interrogações. Destacamos que nas instituições privadas, por exemplo, incertezas econômicas são as que mais preocupam e acabam por afetar as relações sociais. Pais desempregados, mensalidades atrasadas, negociações intermináveis, sem contar a intolerância entre os envolvidos na comunidade escolar. Diante de tantas pressões, insatisfações e limitações encontramos nesse momento, alunos, pais, professores e gestores com reflexos na saúde física, mas em especial emocional, provocadas pelo afastamento social, o que limita as relações.

Vamos fazer um recorte no que diz respeito à autorregulação de uma comunidade educacional. Diante das inúmeras mudanças sociais, LaTaille (2001, p. 16) ressalta que "a pessoa é moralmente autônoma se, apesar das mudanças de contexto 
e da presença das pressões sociais ela permanece, na prática, fiel aos seus valores e a seus princípios de ações". É inegável que vivemos um momento carregado de pressões dentro de um contexto jamais visto.

Pesquisas nacionais e internacionais (ARAÚJO, 1993; BAGAT, 1986; DE VRIES; ZAN, 1998; TOGNETTA, 2003; VINHA 2000, 2003) indicam que as escolas inevitavelmente influenciam de modo significativo na formação das crianças e jovens. Quanto mais o ambiente oferecido for cooperativo, maior o desenvolvimento da autonomia, e; quanto mais autoritário, maiores os níveis de heteronomia.

Vivemos em uma sociedade pautada pelo medo e cada vez mais as pessoas desconfiam da política, da justiça e se resguardam em suas casas. Oportuno mencionar a instalação de mecanismos de segurança com câmeras e alarmes, somando-se a tudo isso agora seguimos todo um protocolo ao sair e chegar em casa, também reflexo do pavor de um vírus que traiçoeiramente pode ceifar a vida de quem amamos.

Trazendo para o contexto escolar atual, crianças não são autônomas e precisam de toda assistência do adulto para manejar as novas ferramentas, pois essas não são de domínio de todos e o medo toma conta a ponto de colocar em dúvida os serviços ali prestados pela instituição educacional.

Fatores externos e inúmeras situações podem ocorrer nesse novo formato. Uma simples atualização para segurança da plataforma pode tirá-la do ar e se isso ocorre em determinado momento em que a família se organizou para executar tal atividade, coloca em dúvida o investimento financeiro. O fator distância pode provocar inúmeros questionamentos quanto ao procedimento pedagógico e o quanto ele atende de fato às necessidades do aluno. Uma sobrecarga da internet próxima à residência do professor e o fato de ele não conseguir ministrar a aula naquele momento coloca em xeque a produtividade do mesmo.

Quando ocorre conflito nas interações sociais as relações acabam sendo estremecidas e em alguns momentos até 
provocar incivilidades no trato da família com a instituição de ensino, revelando insatisfações, podendo eventualmente serem presenciadas por crianças e adolescentes. No entanto é preciso buscar soluções aceitáveis e respeitosas para tratar com a parte envolvida e que se sente prejudicada. Essa disposição em sanar, orientar, facilitar e suprir as necessidades de pais e alunos nesse momento abre a oportunidade para o diálogo e pode ser um fator determinante para o desenvolvimento do clima escolar estremecido pela pandemia.

Vinha e Tognetta (2009, p. 536) defendem a ideia de que relações justas, autônomas, respeitosas e solidárias são necessárias para a tomada de consciência e que a ética está presente nas diversas categorias de uma instituição educacional.

Trago as palavras de Arroyo (2011, p. 47):

A capacidade de escuta sempre atenta e renovada da realidade onde se forma as crianças, adolescentes e jovens faz parte do nosso dever de ofício. A arte de diagnosticar, auscultar, perceber; é tão importante nos profissionais da saúde quanto a capacidade e o tino para regular e intervir. Todo ofício é uma arte reinventada que supõe sensibilidade, intuição, sintonia com a vida, com o humano.

O presente trabalho foi fundamentado por entrevistas com o corpo docente, gestores e servidores em diferentes setores da instituição escolar, com um recorte no período de 26 de março a 15 de maio de 2020. Nessas entrevistas conseguimos informações importantes para o desenvolvimento da nossa pesquisa, alicerçadas por consultas bibliográficas em livros e artigos para embasamento teórico que trouxeram luz às inquietações transcritas na coleta de dados por meio de questionários e áudios transcritos. Importante destacar que o estudo ocorreu durante período de isolamento social.

Documentos oficiais como diretrizes educacionais também compuseram o material de pesquisa, tornando-o mais próximo da realidade. 


\section{GRÁFICO COM O PERFIL DO DOCENTE}

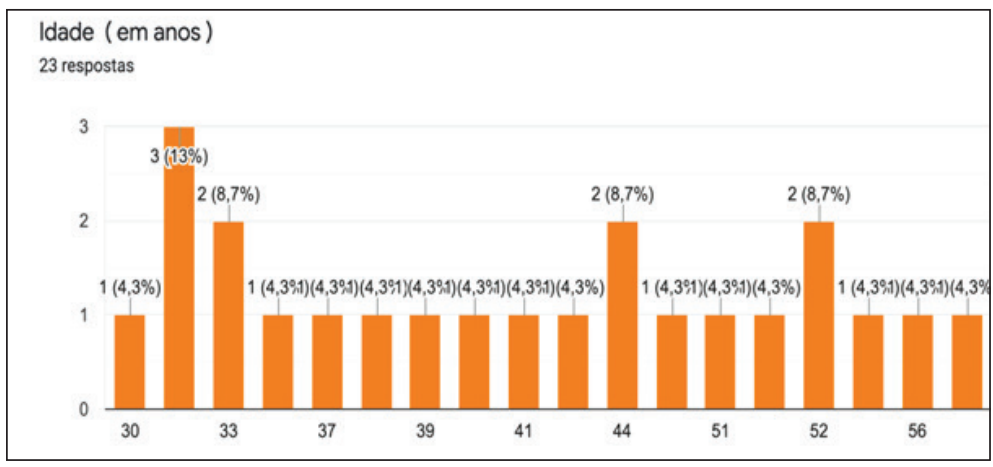

\section{sexo}

23 respostas

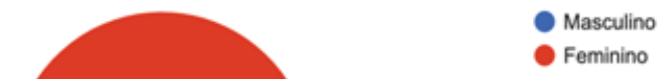

\section{$73,9 \%$}

$26,1 \%$

Estado Civil

23 respostas

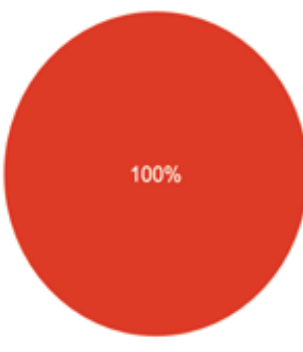

Solteiro(a)

Casado(a)

Viuvo(a)

Divorciado(a)

Outros

Fonte: Instituição Escolar - 2020 
Nas entrevistas que realizamos com a equipe escolar colhemos informações importantes para nossa análise. Entre elas chamamos atenção para a dificuldade de acesso e domínio dos aplicativos nos dispositivos móveis dos pais, o que deixa evidente o quanto ainda não nos apropriamos das tecnologias. É importante que a comunidade de uma maneira geral entenda que o fato de se estar conectado às redes sociais não implica no domínio das inúmeras possibilidades que a tecnologia tem a oferecer.

Um outro fator predominante de insatisfação se dá pelo fato de as famílias não estarem adequadas aos seus pacotes de dados móveis bem como aos aplicativos necessários para ter acesso às aulas remotas e ao conteúdo baixado da plataforma utilizada pela instituição.

A demora no retorno quanto às dúvidas dificultou a aceitação dessa nova metodologia de ensino por parte dos pais, que se demonstram inseguros em acreditar em um processo de aprendizagem no novo formato.

Muitas questões foram administradas pelos gestores, como salários, solicitações de redução de carga horária, demissões, enfim, decisões que o gestor precisou gerenciar e que certamente não estavam em seus planos logo no início de um ano letivo.

Coube ao coordenador pedagógico motivar o profissional a encarar os novos desafios de forma mais tranquila e natural possível, sem destituir a autonomia do mesmo - constatamos nas entrevistas que foi quase impossível.

O diálogo foi a ferramenta que a coordenação encontrou para lidar com todas as questões desencadeadas durante esse período. 
Quanto tempo você teve como periodo de adaptação para nova realidade?

23 respostas

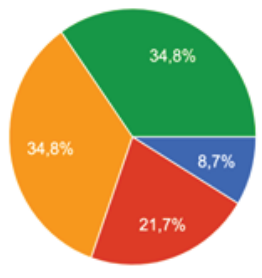

de 01 a 03 dias

de 03 a 05 dias

de 05 a 10 dias

- Não tivemos tempo de adaptaçăo?

Percebemos que apesar da coordenação ter uma preocupação em não tirar a autonomia do professor, inevitavelmente ela aconteceu e ficou clara na pesquisa.

\section{Nesse periodo sua autonomia foi cerceada?}

23 respostas

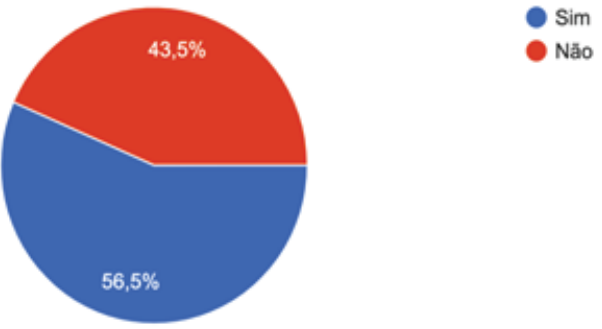

Algumas perguntas revelam as relações entre pares e gestores e encontramos os seguintes resultados:

Você teve um ambiente de trabalho calmo e agradável durante a adequação?

23 respostas

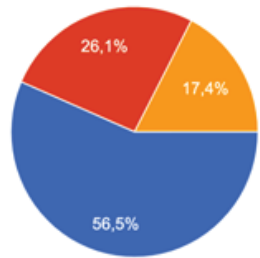

- Sim

Não tenho opinião 


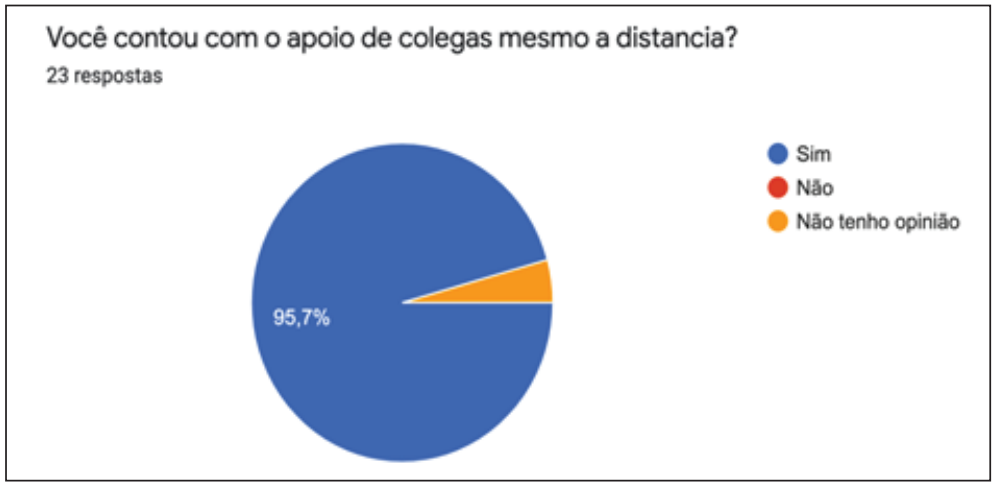

Em relação a comunicação, conseguiu acompanhar as mensagens enviadas no grupo durante a adequação a comunicação era inevitável.

23 respostas

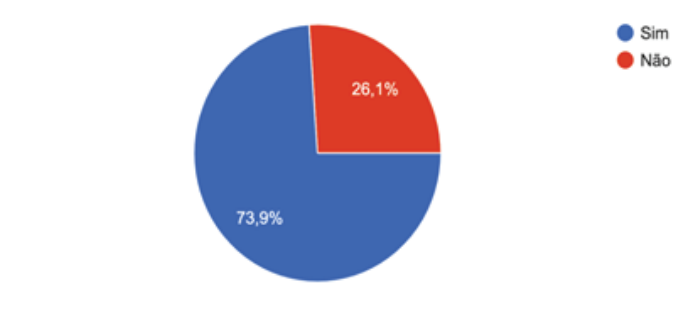

Você se sente mais produtivo trabalhando em casa?

23 respostas

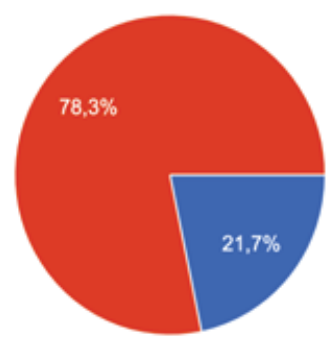


Nas relações com os superiores, o distanciamento favoreceu a boa convivência?

23 respostas

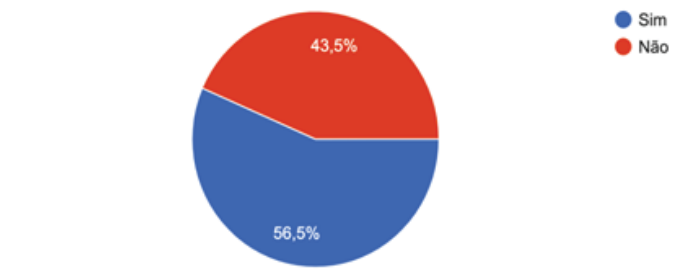

No tocante ao SUPORTE o distanciamento afetou no retorno das suas solicitações feitas ao seus gestores?

23 respostas

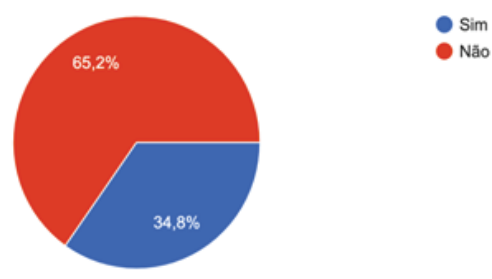

Os gráficos não foram divergentes em relação à comunidade escolar interna, o que pode favorecer e muito na melhoria das relações entre gestores e docentes.

\section{CONSIDERAÇÕES FINAIS}

Ainda que seja um trabalho de análise de um período histórico com tantas interferências nas relações, é importante sermos conscientes de que a superação de cada dificuldade apresentada inclui todos os envolvidos em uma comunidade escolar, e o diálogo e o respeito serão fortes aliados para combater a cultura do individualismo.

É preciso favorecer a construção das relações humanas respeitosas, pautadas em confiança, demonstrando interesse, respeito às dificuldades do outro e reconhecendo as suas próprias. 
A Covid 19 tornou-se protagonista histórica e nós precisaremos passar por todas as interferências causadas por ela. A civilidade compartilhada pela instituição educacional reconhecida por direito como a entidade que trabalha as boas relações, precisa dar exemplo para outras instituições. "Ressalta-se, todavia, que de modo a efetivamente ter êxito, a educação para valores e a convivência não pode se restringir a iniciativas isoladas." (PILEGGI, T. V. et al., 2016, p.115).

Em estudos futuros poderemos nos aprofundar em ações desenvolvidas junto às instituições responsáveis pela formação do professor, pensando na elaboração curricular e o quanto a boa convivência favorece o processo de ensino aprendizagem.

\section{REFERÊNCIAS}

ARROYO, M. G. Ofício de Mestre imagens e autoimagens. Petrópolis-RJ: Vozes, 2011, p.47.

FREIRE, P. Pedagogia da Autonomia: saberes necessários a prática educativa. São Paulo-SP Paz e Terra, 2011.

LA TAILlE, Y. Autonomia e identidade. Revista Criança do Professor de Educação Infantil. Brasília: nome da editora, 2001.

LIMA, L. D. O. A construção do homem Segundo Piaget: Uma teoria da educação. São Paulo-SP Summus editorial, 1984.

PILEGGI, T. V.; TOGNET'TA, L. R. P. Construindo a autonomia moral na escola: os conflitos interpessoais e a aprendizagem dos valores. Revista Diálogo Educacional, v. 9, n.28, 2009.

PILEGGI, T. V.; et al. O clima escolar e a convivência respeitosa nas instituições educativas, Estudos em avaliação educacional. São Paulo - SP Fundação Carlos Chagas, v. 27, n. 64, 2016.

PORTAL ABMES - ASSOCIAÇÃO BRASILEIRA DE MANTENEDORAS DE ENSINO SUPERIOR, disponível em:

https://abmes.org.br/legislacoes/detalhe/3116/parecer-cne-cp-n-5. Acesso em 28 de Abril de 2020

SAINT-EXUPÉRY..A.; Carta a um Refém. Editora Schwarcz - Companhia das Letras, São Paulo-SP, 2018

SANTOS, B. de S. A Cruel pedagogia do Vírus. Coimbra: Almeida, 2020. 